\title{
Gallbladder Volvulus: An Uncommon Phenomenon: A Case Report and Review of the Literature
}

\author{
Padmike Dayananda $^{1^{*}}$, Ramsh Dhamodaran Praba ${ }^{2}$ and Mohommed Rafaideen Balal ${ }^{2}$ \\ ${ }^{1}$ Bunbury Regional Hospital, Bunbury, Australia \\ ${ }^{2}$ Fiona Stanley Hospital, Murdoch Drive, Australia
}

*Corresponding author: Padmike Dayananda, Surgical Registrar, Bunbury Regional Hospital, Bunbury, WA 6230, Perth, Australia, Tel: +61404748272, E-mail:drpadmike@gmail.com

\begin{abstract}
Gallbladder volvulus (GV) is an uncommon cause for abdominal pain and occurs due to rotation of gall bladder on its mesentery along the axis of the cystic duct and the cystic artery [1]. Although it is often misdiagnosed as acute cholecystitis (AC) before surgery, critical constellation of presenting signs and symptoms which guide the emergency physician and surgeon to accurate and timely diagnosis of GV before surgical intervention [2]. We present 52-year-old lady admitted with sudden onset RUQ pain and USS confirmed cholycystitis. At surgery, gangrenous, rotated gall bladder was observed, and cholecystectomy was performed.
\end{abstract}

\section{Keywords}

Gallbladder volvulus, Acute cholecystitis, Cystic duct, Cystic artery, Cholecystectomy

\section{Case Report}

52-year-old lady presented to us with increasing right upper quadrant (RUQ) pain for 2 days with continuous nausea, malaise and subjective fever. No significant background medical history except hypercholesterolemia. On examination, she is borderline obese, BMI 28 and not icteric. RUQ is tender in palpation; murphy's positive and tender in percussion. Her vital signs were stable, respiratory rate 18 , Oxygen saturation $>98$ on room air, heart rate 88 beats per minute and regular, blood pressure 148/76 and temperature 36.9 centigrade. Laboratory investigations showed slightly increased white cell count to 12.8 , increased $C$ reactive protein to 44 and normal liver function tests. Initial ultra sound scan revealed a picture of acalculus cholecystitis with mobile sludge in the gall bladder. She has un- dergone laparoscopic cholecystectomy in the following day and found gangrenous rotated gallbladder. The gall bladder was not perforated at the time of surgery but gangrenous due to rotation along its long axis.

\section{Discussion}

GV is first reported by Wendel in 1898 and dubbed the floating gallbladder [3] and there have been no more than 300 documented cases in the literature ranging from ages 2 to 100 -years-old $[4,5]$. Clinical incidence of GV has been reported as 1:365,520 hospital admissions [2].

There are 5 recognised position of the gallbladder in relation to the liver. 1) Completely embedded in the liver; 2 ) Closely attached to the under surface of the liver by the peritoneum; 3) A complete mesentery but held closely to the liver; 4) A complete mesentery which is long and allow gallbladder to hang freely; 5) An incomplete mesentery which is attached along the cystic duct and allow gallbladder to hang freely in the peritoneum cavity. Only situation 4 and 5 can predispose to torsion.

GV is characterised by mechanical clockwise or counter clockwise organo-axial torsion along the longitudinal axis of the gallbladder involving cystic artery and cystic duct [3]. This rotation causes ischemia and interrupts bile flow, which is responsible for clinical signs and symptoms [1]. It has been suggested that of the clockwise rotation, peristalsis of colon may be responsible, and the anticlockwise rotation is initiated by the peristalsis of the stomach [6].

Loss of visceral fat, liver atrophy, presence of a long

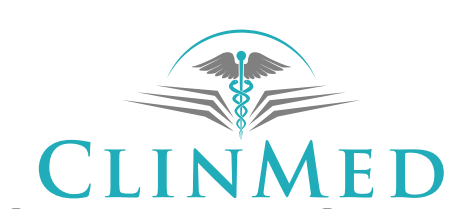

INTERNATIONAL LIBRARY
Citation: Dayananda P, Praba RD, Balal MR (2018) Gallbladder Volvulus: An Uncommon Phenomenon: A Case Report and Review of the Literature. Clin Med Rev Case Rep 5:213. doi.org/10.23937/2378-3656/1410213 Accepted: May 24, 2018: Published: May 26, 2018

Copyright: (c) 2018 Dayananda P, et al. This is an open-access article distributed under the terms of the Creative Commons Attribution License, which permits unrestricted use, distribution, and reproduction in any medium, provided the original author and source are credited. 
mesentery seems to be the major etiological factors. Weight loss and spinal deformities are the other predisposing factors [1]. Role of gallstones is insignificant because more than $50 \%$ of the patient had no gallstones. Except for isolated cases reported in children, this disease is more frequent in elderly patients with a peak incidence of 65-75 year old groups, and a 3:1 female predominance [6]. A few cases have been reported in children $[2,4,7,8]$.

Several conditions are included among the list of risk factors associated with GV.

- Age $>70$ years

- Female sex

- Weight loss

- Liver atrophy

- Kyphoscoliosis

- Atherosclerosis

- Elongated mesentery

- Loss of visceral fat which results in the elongated gallbladder mesentery necessary for torsion to occur [2].

Congenital anomalies that predispose individuals to elongate mesenteries have been reported but these are unusual and undetectable preoperatively [2]. There are two types of congenital abnormalities according to the Gross classification: Type A is long wide mesocyst and type $B$ is incomplete mesocyst [8].

Incomplete volvulus may be misdiagnosed as biliary colic whereas complete torsion produces unremitting, acute RUQ pain mimicking $A C$ and this ultimately results in infarction followed by perforation if not diagnosed promptly [2].

GV is frequently misdiagnosed as acute acalculous cholecystitis as no single clinical, serologic or radiographic finding is pathognomonic [2]. Lau, et al. has described a 3 triads that suggestive of GV.

1. Patient's characteristics - thin, old patients with chronic lung disease or a spinal deformity.

2. Symptoms - abdominal pain, short duration, early onset of vomiting.

3. Signs - abdominal mass, lack of toxaemia or jaundice, discrepancy in the pulse and the temperature.

The clinical presentation is a combination of severe RUQ pain, abdominal guarding and occasionally palpable painful gallbladder. It is worth nothing that palpable RUQ mass is typically present with GV, but the intraabdominal tumour may be missed because of marked guarding [2]. Laboratory evaluations are often non-specific [5]. Despite technological advances in various imaging modalities, definitive diagnosis is generally achieved intra-operatively [3]. Only 4 cases reported in the liter- ature diagnosed pre-operative imaging; the reminder found intra-operatively [3].

Ultrasound scan is the first line investigation, can reveal a clinical picture similar to that of AC but many authors report that ultrasound scan can also be extremely specific in diagnosing torsion when gallbladder is located outside of the fossa and inferior to the liver. This is described as wondering or pedunculated gallbladder. When colour flow Doppler is used to visualise arterial blood, complete volvulus can be effectively eliminated. CT scan is usually nonspecific for diagnosing the disease.

MRI scan MRCP can demonstrate necrosis or infarction or both while hepatobiliary Iminodiacetic Acid scans of GV are reported to resemble a bull's-eye because accumulation of radioactive tracer within the gallbladder [2,5].

Although GV is a rare occurrence, the diagnosis should considered in all patients presenting with RUQ pain [5]. Once GV diagnosed, the appropriate treatment is emergency cholecystectomy. This can be performed by laparoscopic, which is firstly performed by Schroder and Cusumano in 1994, or open technique. Prognosis is excellent if expeditious cholecystectomy is performed, if treatment is delayed, infarction and perforation resulting in bilious peritonitis increase the mortality rate up to $5 \%$ [2].

\section{Conclusion}

GV is relatively uncommon phenomenon making pre-operative diagnosis difficult. Detailed history and clinical examination with a high index of suspicion in the outlined patient demographic will help for pre-operative diagnosis of GV. The prompt diagnosis is critical to ensure that patient undergoes urgent detorsion and cholecystectomy avoiding fatal complications.

\section{Consent}

Informed consent was obtained from the patient for publication of this case report and for laboratory investigations.

\section{References}

1. Engin DA, Oktay $\mathrm{H}$, Bunyamin $\mathrm{U}$, Baris $\mathrm{O}$, Elif $\mathrm{K}$, et al. (2012) Gallbladder volvulus. Journal of Pakistan Medical Association 18: 66-69.

2. Brian JP, Leonardo A, Harris WH (2013) A clinician's guide to the diagnosis and management of gallbladder volvulus. Perm J 17: 80-83.

3. Mouawad NJ, Crofts B, Streu R, Desrochers R, Kimball BC (2011) Acute gallbladder torsion- a continued pre-operative diagnostic dilemma. World Journal of Emergency Surgery 6: 13.

4. Shaikh AA, Charles A, Domingo S, Schaub G (2005) Gallbladder volvulus: Report of two original cases and review of the literature. Am Surg 71: 87-89.

5. Matsuhashi N, Satake S, Yawata K, Asakawa E, Mizoguchi T, et al. (2006) Volvulus of the gallbladder diagnosed by 
ultrasonography, computed tomography, coronal magnetic resonance imaging and magnetic resonance cholagio-pancreatography. World J Gastroenterol 12: 4599-4601.

6. Gupta V, Singh V, Sewkani A, Purohit D, Varshney R, et al. (2009) Torsion of gallbladder, a rare entity: A case report and review article. Cases J 2: 193.
7. Tarhan OR, Barut I, Dinelek H (2006) Gallbladder volvulus: review of the literature and report of a case. Turk J Gastroenterol 17: 209-211.

8. Gog A, Robert B, Mouly C, Castier M, Chivot C, et al. (2003) Gallbladder volvulus: A rare case of acute cholecystitis. Diagn Interv Imaging 94: 893-895. 